\title{
A short focus, azithromycin in the treatment of respiratory viral infection COVID-19: efficacy or inefficacy?
}

\author{
Antonio Vitiello $^{1}$ (D) Francesco Ferrara ${ }^{2} \mathbb{D}$ \\ Received: 28 June 2021 / Accepted: 7 October 2021 / Published online: 5 November 2021 \\ (c) The Author(s), under exclusive licence to Springer Science+Business Media, LLC, part of Springer Nature 2021
}

\begin{abstract}
Azithromycin is a macrolide antibiotic. Recent evidence has demonstrated in vitro activity against a wide variety of respiratory tract viruses, including SARS-CoV-2 responsible for the current global pandemic COVID-19. A mechanism of action acting on different phases of the viral cycle is assumed. In addition to its in vitro antiviral properties, some evidence also suggests immunomodulatory and antifibrotic activity. These properties of azithromycin could be useful in the treatment of viral respiratory tract infections such as COVID-19. However, clinical data on the antiviral efficacy of azithromycin in the treatment of respiratory tract infections are inconsistent, both when used as monotherapy and in polypharmacological combination. In addition, cases of azithromycin-induced QT long and malignant arrhythmias are reported. In this short review, we attempt to determine the role of azithromycin in the treatment of viral respiratory tract infections such as COVID-19, therapeutic efficacy, or inefficacy?
\end{abstract}

Keywords Azithromycin · Pneumonia $\cdot$ Pulmonary $\cdot$ Virology

\section{Introduction}

To date, there are no antivirals directed against SARS-CoV-2 $[1,2]$. Pharmacological treatments used are directed at avoiding serious complications of infection [3-6]. Antiviral and immunomodulatory agents used are some of the pharmacological options proposed [7-10]. Various pharmacological agents such as remdesivir, dexamethasone, colchicine, baricitinib, and tocilizumab have been studied, with mixed results [11-14]. In view of the viral cycle of SARS-CoV-2, several potential molecular targets for the use of antiviral agents can be considered. One molecular target could be the inhibition of endocellular penetration of the virus by acting on the entry receptor ACE-2 [15-17], the (S) spike protein, and the transmembrane serine protease type II (TMPRSS2). Another target is the inhibition of viral replication by acting

Francesco Ferrara

ferrarafr@libero.it

Antonio Vitiello

antonio.vitiello2@uslumbria1.it

1 Pharmaceutical Department, Usl Umbria 1, A.Migliorati Street, 06,132, Perugia, Italy

2 Pharmaceutical Department, Asl Napoli 3 Sud, Dell'amicizia Street 22, 80035 Naples, Nola, Italy on virus proteinases. In addition, another molecular target is represented by viral structural proteins such as envelope protein $\mathrm{E}$ or membrane protein $\mathrm{M}[18,19]$. In association with drugs with SARS-CoV-2 antiviral activity, pharmacological agents directed at reducing the generalized hyperinflammatory state caused by the cytokinic storm are used. In general, for all of these pharmacologic agents, the clinical evidence is conflicting [20]. Among the clinical trials conducted, only remdesivir and corticosteroids improved clinical outcomes in patients hospitalized with SARS-CoV-2. Azithromycin is an antibacterial of the macrolide class; some evidence has associated potential antiviral and immunomodulatory therapeutic efficacy, in monotherapy and in combination, for the treatment of SARS-CoV-2 infection [21], although further clinical evidence is needed to demonstrate the true therapeutic role of azithromycin in viral infections of the respiratory tract.

\section{Azithromycin in the treatment of respiratory viral infections}

In vitro evidence has shown for azithromycin antiviral activity against many respiratory viruses [22]. Azithromycin use inhibited rhinovirus replication at 10 and $50 \mu \mathrm{M}$ [23]. In 
Zika virus, the use of azithromycin showed an EC50 of 1.23-6.59 $\mu \mathrm{M}$ [24]. Azithromycin also showed in vitro antiviral activity against SARS-CoV-2 with an EC50 of $2.12 \mu \mathrm{M}$, an EC90 of $8.65 \mu \mathrm{M}$, and a cytotoxic concentration of $50 \%>40 \mu \mathrm{M}$. In addition, azithromycin has been associated with immunomodulatory properties [25], which could be potentially useful in the treatment of the hyperinflammatory state caused by the cytokine storm in the most severe stages of COVID-19. In vitro, azithromycin showed a decrease in the secretion of proinflammatory cytokines and chemokines, decreasing the concentration of IL-1 $\beta$, IL-4, IL-5, IL-6, TNF- $\alpha$, and GM-CSF [26] and increasing the release of an anti-inflammatory cytokine (IL-10) related to the repair of inflamed tissues [27]. In lymphocytes, azithromycin was shown to suppress the activation of $\mathrm{CD} 4+\mathrm{T}$ cells. Azithromycin also has been shown to reduce the accumulation of inflammatory cells in the bronchoalveolar lavage [28]. In addition in fibroblasts, it has been shown to inhibit proliferation and collagen production by reducing the concentration of transforming growth factor (TGF$\beta)$ and demonstrating pulmonary antifibrotic activity [29, 30]. Finally, azithromycin is associated with a mucoregulatory effect, reducing mucus hypersecretion and improving mucociliary clearance [31]. Several mechanisms of antiviral action against SARS-CoV-2 have been proposed. Among them, studies have suggested that azithromycin may alter ACE2 glycosylation and prevent endocellular penetration of the virus. Another proposed mechanism of antiviral action suggests that azithromycin is a GM1 ganglioside-mimetic. The SARS-CoV-2 spike protein shows a binding site to gangliosides; azithromycin binding to this target prevents the virus spike protein from reaching gangliosides on the host plasma membrane [32].

\section{Clinical efficacy}

A clinical study demonstrated that signs and symptoms of SARS-CoV-2 infection were significantly reduced in response to a treatment regimen containing hydroxychloroquine and azithromycin. The most common side effects reported were stomach pain, hypoglycemia, dizziness, pruritus, rash, and QT prolongation [33]. Another study conducted demonstrated the efficacy of the combination of hydroxychloroquine and azithromycin on both viral clearance and shorter hospitalization time for COVID-19 patients [34]. Another study conducted in 16,442 hospitalized SARS-CoV-2 patients demonstrated that azithromycin did not improve survival or other prespecified clinical outcomes concluding that the use of azithromycin in hospitalized COVID-19 patients should be limited to patients in whom there is a clear antimicrobial indication [35]. A large study conducted demonstrated that the findings do not justify the routine use of azithromycin to reduce recovery time or risk of hospitalization for persons with suspected SARS-CoV-2 infection [36]. These findings have important implications, as inappropriate antibiotic use leads to increased antimicrobial resistance. However, the risk benefit profile of azithromycin in severe COVID-19 patients has yet to be fully identified. To date, there are many ongoing registered clinical trials regarding the use of azithromycin alone or in combination for SARS-CoV-2 infection treatment.

\section{Safety}

The therapeutic treatment of SARS-CoV-2 infection is complex and involves the administration of multiple pharmacologic agents. Polypharmacy may increase the risk of drug-drug interactions. The most common side effects reported during treatment with azithromycin are gastrointestinal, such as diarrhea, abdominal pain, and nausea. However, some macrolides are well-known to be primogenic. The proarrhythmogenic effects of azithromycin have been demonstrated in preclinical trials showing that azithromycin increases the QT interval and the duration of the action potential $[37,38]$. Several observational studies have investigated the association of cardiovascular death (as a potential consequence of QT prolongation) with azithromycin use. In light of the data described above, any administration of azithromycin and hydroxychloroquine, and azithromycin in association with remdesivir, should be carefully monitored, as these are drugs that may prolong QT. In the largest reported cohort of patients with coronavirus disease 2019 to date treated with chloroquine/hydroxychloroquine \pm azithromycin, no cases of torsade de pointes or arrhythmogenic death were reported. Although the use of these drugs has resulted in QT prolongation, physicians have rarely had to discontinue therapy [39]. In addition, dosage modification should also be considered for azithromycin in cases of decreased hepatic and renal function to avoid increased plasma concentrations and risk of QT long. The risk of druginduced arrhythmias is much higher in critical COVID-19 patients. In addition, silent genetic variants of QT long, present in approximately $4 \%$ of people, may make a person more vulnerable to malignant and fatal arrhythmias from azithromycin. Finally, in the severe COVID-19 patient, other risk factors that may cause arrhythmias in the COVID-19 patient should be considered, for example, hypokalemia, profound hypoxemia, and cytokine storm [40, 41] (Table 1).

\section{Discussion}

Azithromycin has, in addition to antibacterial effects, antiviral and immunomodulatory properties that could be useful in the treatment of the various stages of SARS-CoV-2 infection. Although the use of azithromycin has been associated 


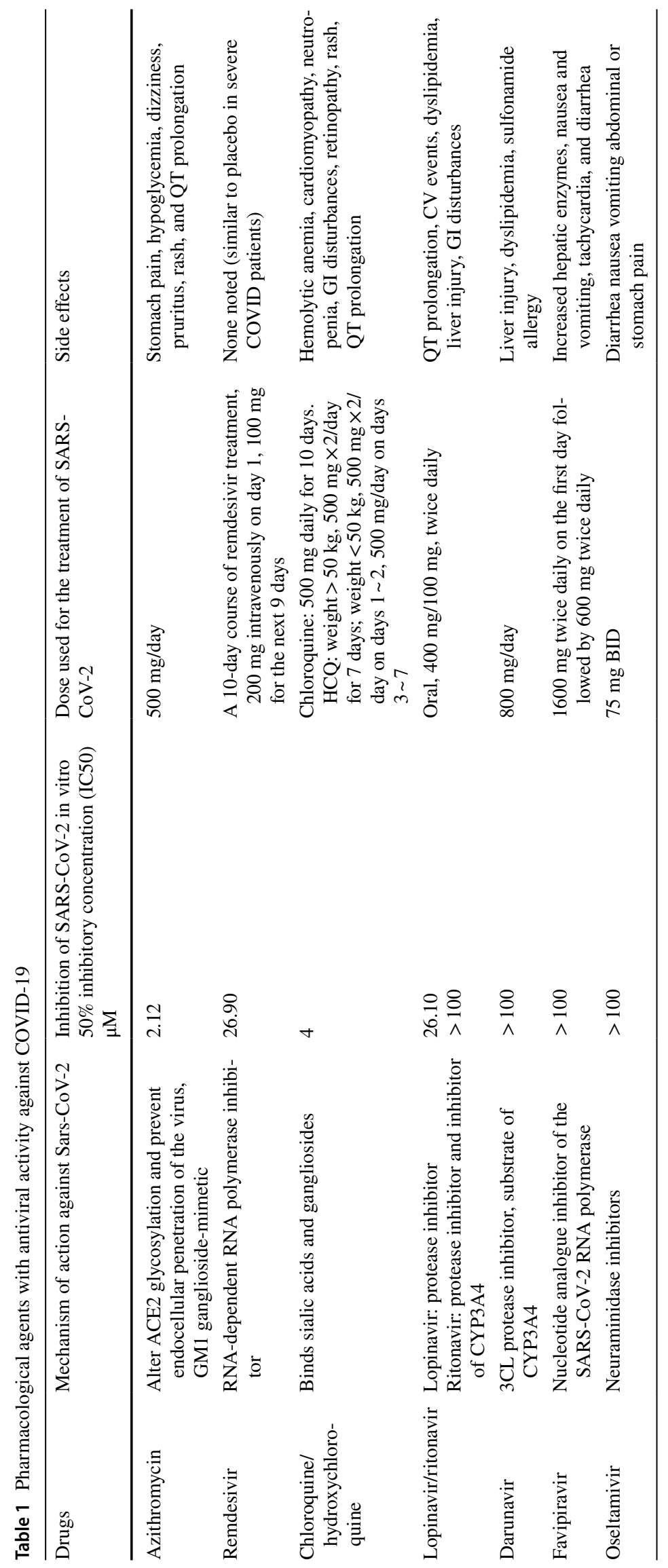


with clinical improvements in several viral infections of the respiratory tract, for the treatment of SARS-CoV-2 infection to date, the clinical evidence does not coincide with the in vitro evidence. Azithromycin in fact has shown in vitro antiviral activity against SARS-CoV-2, acting at different points of the viral cycle including the binding or activation of the fusion process by lysosomal proteases. Furthermore, given that in the most severe stages of SARS-CoV-2 infection the hyperinflammatory state caused by the cytokine storm is responsible for the severe lesions, the potential of azithromycin to reduce cytokine production, preserve epithelial integrity, and prevent lung fibrosis could play an important role. Probably the paucity of clinical efficacy data for azithromycin is a consequence of this macrolide being mostly administered with hydroxychloroquine, which has been shown to provide no benefit in the treatment of SARSCoV-2 pneumonia. In addition, the paucity of clinical data also stems from the failure to identify an optimal dose of azithromycin. According to the RECOVERY study, in severe patients, $500 \mathrm{mg} /$ day should be used. However, in view of the pharmacokinetic properties of azithromycin to concentrate in the respiratory tract and lungs, allowing the achievement of optimal and prolonged therapeutic concentrations, and that immunomodulatory and antiviral actions could be achieved with lower doses, one could consider the hypothesis that the benefits obtained with this macrolide could be obtained with lower and safer doses. Future clinical trials will determine the optimal dose of this drug in this context. Finally, azithromycin has not yet been adequately studied in which subgroup of patients it might offer the greatest clinical benefit.

\section{Conclusions}

In the context of pharmacological treatment of SARS-CoV-2 infection, azithromycin has demonstrated inconsistencies between in vitro and clinical evidence. Azithromycin has a well-known safety profile, some safety concerns have been raised because of its potential cardiotoxicity, especially when combined with hydroxychloroquine, in COVID-19 patients.

To date, there is no clear evidence demonstrating the efficacy of azithromycin use in COVID-19 patients; further clinical trials are needed to identify the optimal dose in COVID-19 patients. The use of drugs with potential proarrhythmogenic effect such as azithromycin in severe COVID19 patients should be carefully monitored.

Author contribution All authors contributed equally to the manuscript and had the opportunity to revise and approve the final text

\section{Declarations}

Ethics approval and consent to participate Not applicable.

Consent for publication No available supporting data.

Conflict of interest The authors declare no competing interests.

\section{References}

1. Becker RC. Covid-19 treatment update: follow the scientific evidence. J Thromb Thrombolysis. 2020;50(1):43-53. https://doi.org/ 10.1007/s11239-020-02120-9.

2. Trivedi N, Verma A, Kumar D. Possible treatment and strategies for COVID-19: review and assessment. Eur Rev Med Pharmacol Sci. 2020;24(23):12593-608. https://doi.org/10.26355/eurrev 202012_24057.

3. Ferrara F, Porta R, D'Aiuto V, Vitiello A. Remdesivir and COVID-19. Ir J Med Sci. 2020;17:1-2. https://doi.org/10.1007/ s11845-020-02401-5.

4. Vitiello A, Ferrara F. Correlation between renin-angiotensin system and severe acute respiratory syndrome coronavirus 2 infection: what do we know? Eur J Pharmacol. 2020;15(883): 173373. https://doi.org/10.1016/j.ejphar.2020.173373.

5. Vitiello A, Ferrara F, Pelliccia C, Granata G, La Porta R. Cytokine storm and colchicine potential role in fighting SARS-CoV-2 pneumonia. Italian Journal of Medicine. 2020;14(2):88-94. https://doi. org/10.4081/itjm.2020.124.

6. Vitiello A, Ferrara F. Pharmacological agents to therapeutic treatment of cardiac injury caused by Covid-19. Life Sci. 2020;1(262): 118510. https://doi.org/10.1016/j.lfs.2020.118510.

7. Vitiello A, Ferrara F. Therapeutic strategies for SARS-CoV-2 acting on ACE-2. Eur J Pharm Sci. 2021;1(156): 105579. https://doi. org/10.1016/j.ejps.2020.105579.

8. Vitiello A, Ferrara F. Remdesivir versus ritonavir/lopinavir in COVID-19 patients. Ir J Med Sci. 2020;18:1-2. https://doi.org/ 10.1007/s11845-020-02440-y.

9. Vitiello A, La Porta R, Ferrara F. Scientific hypothesis and rational pharmacological for the use of sacubitril/valsartan in cardiac damage caused by COVID-19. Medical Hypotheses. 2021;110486:0306-9877. https://doi.org/10.1016/j.mehy.2021. 110486.

10. Vitiello A, Ferrara F, La Porta R. Remdesivir and COVID-19 infection, therapeutic benefits or unnecessary risks?2020. https:// doi.org/10.1007/s11845-020-02482-2

11. Ferrara F, Vitiello A. Efficacy of synthetic glucocorticoids in COVID-19 endothelites Naunyn-Schmiedeberg's Archives of Pharmacology. 2021. https://doi.org/10.1007/s00210-021-02049-7

12 Vitiello A, Pelliccia C, Ferrara F, Drugs acting on the reninangiotensin system and SARS-CoV-2, Drug Discovery Today, 2021,ISSN 1359-6446, https://doi.org/10.1016/j.drudis.2021.01. 010.

13. Vitiello A, La Porta R, D’Aiuto V, Ferrara F. Pharmacological approach for the reduction of inflammatory and prothrombotic hyperactive state in COVID-19 positive patients by acting on complement cascade. Hum Immunol. 2021. https://doi.org/10.1016/j. humimm.2021.01.007.

14 Vitiello A, Ferrara F. Colchicine and SARS-CoV-2: management of the hyperinflammatory state. Respiratory Medicine. 2021;178(106322):0954-6111. https://doi.org/10.1016/j.rmed. 2021.106322.

15. Ferrara F, Vitiello A. Potential pharmacological approach in the regulation of ACE-2 and DPP-IV in diabetic COVID-19 patient. 
Italian Journal of Medicine, (AOP). 2020. https://doi.org/10.4081/ itjm.2020.1435.

16. Ferrara F, Vitiello A. Scientific hypothesis for treatment of COVID-19's lung lesions by adjusting ACE/ACE2 imbalance. Cardiovasc Toxicol. 2021;9:1-6. https://doi.org/10.1007/ s12012-021-09649-y.

17. Vitiello A, Ferrara F. Pharmacological agents modifying the renin angiotensin and natriuretic peptide systems in COVID-19 patients. Wien Klin Wochenschr. 2021. https://doi.org/10.1007/ s00508-021-01855-6.

18. Wang MY, Zhao R, Gao LJ, Gao XF, Wang DP, Cao JM. SARSCoV-2: structure, biology, and structure-based therapeutics development. Front Cell Infect Microbiol. 2020;25(10): 587269. https:// doi.org/10.3389/fcimb.2020.587269.

19. Kirtipal N, Bharadwaj S, Kang SG. From SARS to SARS-CoV-2, insights on structure, pathogenicity and immunity aspects of pandemic human coronaviruses. Infect Genet Evol. 2020;85: 104502. https://doi.org/10.1016/j.meegid.2020.104502.

20. Vitiello A, Porta R, Pianesi L, Ferrara F. COVID-19 pandemic: vaccine and new monoclonal antibodies, point of view. Ir J Med Sci. 2021. https://doi.org/10.1007/s11845-021-02584-5.

21. Gautret P, Lagier J-C, Parola P, Hoang VT, Meddeb L, Mailhe M. Hydroxychloroquine and azithromycin as a treatment of COVID19: results of an open-label non-randomized clinical trial. Int J Antimicrob Agents. 2020. https://doi.org/10.1016/j.ijantimicag. 2020.105949.

22. Damle B, Vourvahis M, Wang E, Leaney J, Corrigan B. Clinical pharmacology perspectives on the antiviral activity of azithromycin and use in COVID-19. Clin Pharmacol Ther. 2020;108(2):201-11. https://doi.org/10.1002/cpt.1857.

23. Sajjan US, Jia Y, Newcomb DCH. influenzae potentiates airway epithelial cell responses to rhinovirus by increasing ICAM-1 and TLR3 expression. FASEB J. 2006;20(12):2121-3.

24. Li C, Zu S, Deng YQ. Azithromycin protects against Zika virus infection by upregulating virus-induced type I and III interferon responses. Antimicrob Agents Chemother. 2019;63(12):e00394-e419. https://doi.org/10.1128/AAC. 00394-19.

25. Wilms EB, Touw DJ, Heijerman HG. Pharmacokinetics of azithromycin in plasma, blood, polymorphonuclear neutrophils and sputum during long-term therapy in patients with cystic fibrosis. Ther Drug Monit. 2006;28(2):219-25.

26 Tsai WC, Rodriguez ML, Young KS. Azithromycin blocks neutrophil recruitment in Pseudomonas endobronchial infection. Am J Respir Crit Care Med. 2004;170(12):1331-9.

27. Culic O, Erakovic V, Cepelak I. Azithromycin modulates neutrophil function and circulating inflammatory mediators in healthy human subjects. Eur J Pharmacol. 2002;450(3):277-89.

28. Tsai WC, Standiford TJ. Immunomodulatory effects of macrolides in the lung: lessons from in-vitro and in-vivo models. Curr Pharm des. 2004;10(25):3081-93.

29. Stamatiou R, Paraskeva E, Boukas K, Gourgoulianis KI, Molyvdas PA, Hatziefthimiou AA. Azithromycin has an antiproliferative and autophagic effect on airway smooth muscle cells. Eur Respir J. 2009;34(3):721-30.

30. Cigana C, Assael BM, Melotti P. Azithromycin selectively reduces tumor necrosis factor alpha levels in cystic fibrosis airway epithelial cells. Antimicrob Agents Chemother. 2007;51(3):975-81.

31. Halldorsson S, Gudjonsson T, Gottfredsson M, Singh PK, Gudmundsson GH, Baldursson O. Azithromycin maintains airway epithelial integrity during Pseudomonas aeruginosa infection. Am J Respir Cell Mol Biol. 2010;42(1):62-8.

32. Pani A, Lauriola M, Romandini A, Scaglione F. Macrolides and viral infections: focus on azithromycin in COVID-19 pathology. Int J Antimicrob Agents. 2020;56(2): 106053. https://doi.org/10. 1016/j.ijantimicag.2020.106053.

33. Abbas HM, Al-Jumaili AA, Nassir KF, Al-Obaidy MW, Al Jubouri AM, Dakhil BD, Abdulelah MM, Al Khames QA. Assessment of COVID-19 treatment containing both hydroxychloroquine and azithromycin: a natural clinical trial. Int J Clin Pract. 2021;75(4): e13856. https://doi.org/10.1111/ijcp.13856.

34. Gautret P, Hoang VT, Lagier JC, Raoult D. Effect of hydroxychloroquine and azithromycin as a treatment of COVID-19: results of an open-label non-randomized clinical trial, an update with an intention-to-treat analysis and clinical outcomes. Int $\mathbf{J}$ Antimicrob Agents. 2021;57(1): 106239. https://doi.org/10.1016/j.ijantimicag. 2020.106239.

35. RECOVERY Collaborative Group. Azithromycin in patients admitted to hospital with COVID-19 (RECOVERY): a randomised, controlled, open-label, platform trial. Lancet. 2021;397(10274):605-12. https://doi.org/10.1016/S01406736(21)00149-5.

36. PRINCIPLE Trial Collaborative Group. Azithromycin for community treatment of suspected COVID-19 in people at increased risk of an adverse clinical course in the UK (PRINCIPLE): a randomised, controlled, open-label, adaptive platform trial. Lancet. 2021;397(10279):1063-74. https://doi.org/10.1016/S01406736(21)00461-X.

37. Yang Z, Prinsen JK, Bersell KR, Shen W, Yermalitskaya L, Sidorova T, Luis PB, Hall L, Zhang W, Du L, Milne G, Tucker P, George AL Jr, Campbell CM, Pickett RA, Shaffer CM, Chopra N, Yang T, Knollmann BC, Roden DM, Murray KT. Azithromycin causes a novel proarrhythmic syndrome. Circ Arrhythm Electrophysiol. 2017;10(4): e003560. https://doi.org/10.1161/CIRCEP. 115.003560 .

38. Vogt AW, Zollo RA. Long Q-T syndrome associated with oral erythromycin used in preoperative bowel preparation. Anesth Analg. 1997;85(5):1011-3.

39. Saleh M, Gabriels J, Chang D, Soo Kim B, Mansoor A, Mahmood E, Makker P, Ismail H, Goldner B, Willner J, Beldner S, Mitra R, John R, Chinitz J, Skipitaris N, Mountantonakis S, Epstein LM. Effect of chloroquine, hydroxychloroquine, and azithromycin on the corrected QT interval in patients with SARS-CoV-2 infection. Circ Arrhythm Electrophysiol. 2020;13(6): e008662. https://doi. org/10.1161/CIRCEP.120.008662.E.

40. Lai CC, Ko WC, Lee PI, Jean SS, Hsueh PR. Extra-respiratory manifestations of COVID-19. Int J Antimicrob Agents. 2020;56(2): 106024. https://doi.org/10.1016/j.ijantimicag.2020. 106024.

41. Di Domenico M, De Rosa A, Boccellino M. Detection of SARSCOV-2 proteins using an ELISA Test. Diagnostics (Basel). 2021;11(4):698. https://doi.org/10.3390/diagnostics11040698.

Publisher's Note Springer Nature remains neutral with regard to jurisdictional claims in published maps and institutional affiliations. 